\title{
Confronting Disinformation: Journalists and the Conflict over Truth in \#EIxn43
}

Chris Tenove and Stephanie MacLellan

PRE-PRINT of chapter in: Cyber-Threats to Canadian Democracy, ed. by Holly Ann Garnett and Michael Pal. McGill-Queen's University Press.

\section{Introduction}

There is widespread concern that online disinformation threatens democracy, and in particular the integrity of democratic elections. This concern has been stoked by evidence that both foreign and domestic actors have used a range of techniques to promote false or deceptive content during electoral campaigns, most prominently during the United States election and the United Kingdom's Brexit referendum in 2016 (Communications Security Establishment 2017; Bayer et al. 2019; U.S. Senate 2019). In the run-up to the 2019 federal election in Canada, experts and policymakers raised the possibility that foreign or domestic actors might use disinformation tactics during the campaign. This prompted Canadian journalists to give unprecedented attention to threats that online disinformation might pose to the information ecosystem and thus to electoral integrity.

Journalism organizations have long performed a gatekeeper function: they select and disseminate to the public some but not all information, or information from some but not all sources (Vos 2019). As a result, they play an important role in shaping public discourse during election campaigns (Druckman 2005; McCombs 2014). ${ }^{1}$ As such, they may be better positioned

\footnotetext{
${ }^{1}$ We use the terms "journalism organizations," "news organizations" and "news outlets" interchangeably, to refer to public and private news media organizations that broadly adhere to journalism professional
} 
than other institutions to help the public identify disinformation, and understand the motives and mechanisms behind it. Furthermore, they may play a critical role in informing the public about other cyber-threats to electoral integrity, including cyber-security breaches of political parties or electoral management bodies.

However, journalism organizations have at times had their own reporting practices "hacked" by disinformation actors, leading them to accidentally amplify the reach or impact of disinformation campaigns (Lukito et al. 2020; Phillips 2018; Wardle 2018). Moreover, the rise of online disinformation has come at a time when the journalism field itself is disrupted by threats to its economic viability, its gatekeeping function, and its perceived legitimacy.

This chapter analyzes how Canadian journalists understood and responded to disinformation in the 2019 federal election campaign. (The election was often referred to on social media with the hashtag \#elxn43, because it was Canada's $43^{\text {rd }}$ federal election). We address three research questions: What do journalists identify as forms of disinformation that threaten the quality of public debate during an election campaign? How do journalists believe they should respond to disinformation? What lessons can be drawn from instances of disinformation present in the 2019 election campaign, and from journalism organizations' responses to them?

The chapter proceeds as follows. We first describe the context for journalists' attention to online disinformation as one form of cyber-threat to the integrity of the 2019 election. We next review communication and journalism scholarship on contributions that journalism can make to the democratic quality of elections, and the challenges posed by disinformation actors and by

norms. Defining what counts as a journalism organization is contested, and as noted below this became an issue during the 2019 Canadian election campaign (Loriggio 2019). 
upheaval in the media system. We then explain our methodological approach, the analysis of indepth interviews with more than 30 journalists, conducted before and after the 2019 election campaign. The next section presents our findings on the first research question.

In brief, while interviewees had competing conceptions of disinformation and the appropriate responses by journalists, most associated it with digitally enabled techniques of media manipulation (e.g. the use of automated social media accounts known as "bots") pursued by both traditional and newly prominent actors (including foreign states, partisan organizations and loose networks of domestic trolls). To address online disinformation, some journalism organizations developed new reporting approaches and teams, while many journalists and senior editors reflected on how longstanding reporting practices may or may not address this new challenge. We then investigate key challenges that journalists face in countering disinformation by examining three illustrative cases from the 2019 campaign: the alleged role of bots and foreign accounts in online discourse; the salacious rumours about incumbent prime minister Justin Trudeau pushed by foreign and domestic actors, including the U.S.-based website The Buffalo Chronicle; and the potential for leaks of illegally acquired material acquired through hacking operations.

Reflecting on disinformation in \#elxn43, journalists described three general challenges. Two are relatively new: how to identify novel and sophisticated online disinformation tactics, and how to address disinformation without amplifying its spread on social media. The third is a dilemmas that journalists have long faced in election reporting: how to report on misleading claims in a context of intense partisan competition, when journalists themselves are being scrutinized as actors in the political fray. 


\section{Context: Disinformation as a Threat to Canada's Election Integrity}

Concern that disinformation threatens electoral integrity has increased dramatically in recent years, with evidence of foreign state-sponsored and domestic campaigns of deceptive communication preceding elections in countries including France, Germany, Kenya, Ukraine, the United Kingdom, and the United States (Communications Security Establishment 2017; Bayer et al. 2019; Tenove 2020). In particular, the 2016 U.S. election campaign revealed the many tactics that actors could use to undermine the quality of information and political discussion (U.S. Senate 2019).

Disinformation in elections is not new. However, actors now use new tactics of digital disinformation, which take advantage of vulnerabilities in information systems that have undergone dramatic upheaval in an era of social media platforms (Miller and Vaccari 2020; McKay and Tenove 2020). As we further explain below, one aspect of this upheaval is that journalism organizations play a reduced role as information gatekeepers (Vos 2019). For instance, during the Cold War, Soviet attempts to infiltrate the public discourse were routinely weeded out by professional journalists and editors who "thoroughly vetted stories before publication" (Deeks, McCubbin, and Poplin 2017). Now social media itself has become an important source of news, with platforms allowing any and all users to post links to news stories, comment on current events, and even stream live video of breaking news events (Posetti 2018). Election candidates, hate groups, foreign adversaries, and engaged citizens all have new opportunities to communicate more directly, without intermediation by journalists.

In addition to the overt distribution of information, foreign states and other potentially adversarial actors engage in many forms of covert strategic communications (Bradshaw and Howard 2018). For instance, the Kremlin-linked Internet Research Agency (IRA), the so-called 
"troll factory" that carried out disinformation campaigns in the 2016 U.S. election, created social media accounts that posed as Americans. Doing so enabled them to distort the information environment by making foreign-planted or foreign-amplified opinions look more prevalent than they really were, and to sow distrust among social groups or toward democratic institutions (U.S. Senate 2019). As a result of these and other activities, polling suggests that audiences have difficulty differentiating between reliable news and false information. For instance, an Edelman Trust Barometer global survey (2018) found that $63 \%$ of people do not believe the average person can tell the difference between legitimate journalism and rumours, while 59\% say it is becoming more difficult to tell if a news item was produced by a respected media organization.

The threat of disinformation for \#elxn43

The Canadian government, experts, and journalists warned that the 2019 federal election could be targeted by online disinformation operations. In April 2019, Canada's signals intelligence agency, the Communications Security Establishment $(2019,5)$, issued a report stating it was "very likely that Canadian voters will encounter some form of foreign cyber interference related to the 2019 federal election." The CSE explained that foreign actors may “target the democratic process to change Canadian election outcomes, policy makers' choices, governmental relationships with foreign and domestic partners, and Canada's reputation around the world" (9). This interference would likely entail attempts to manipulate voters, political parties, and journalists via information operations, the CSE declared, because Canada's paperbased federal voting processes are themselves deemed secure (Communications Security Establishment 2017). 
Prior to the 2019 election, there were indications that foreign actors were using disinformation tactics to influence the Canadian public. Evidence emerged in 2018 suggesting that Canadian audiences were targeted by accounts affiliated with the Russian IRA between 2015 and 2017 (Rocha 2018). A small percentage of tweets from these accounts addressed divisive Canadian issues, such as the ongoing debate over the Keystone XL pipeline, which suggested the IRA was testing social media influence operations in Canada.

In an attempt to thwart potential foreign interference in the 2019 election, the Canadian government introduced a range of policies. These included a task force of intelligence and policing agencies to monitor and potentially disrupt interference, and a non-partisan process to enable senior civil servants to alert citizens about election interference in the midst of a campaign (Government of Canada 2019; for a review of these and other measures see Tenove and Tworek 2019). The government also introduced the Elections Modernization Act (Bill C76), in part to address the threat of foreign election interference, which included new political advertising requirements for social media companies.

While the Canadian government primarily focused on potential disinformation campaigns by foreign actors, domestic actors also play a significant role in the propagation of false and deceptive information online (Tenove et al. 2018). Canadian researchers and journalists identified hate groups, terrorist networks, and hyper-partisan organizations as likely domestic or transnational sources of disinformation (Communications Security Establishment 2017; Boutilier 2018). Indeed, in an analysis of the spring 2019 Alberta provincial election campaign, the G7 Rapid Response Mechanism found no significant evidence of foreign interference campaigns, but did find accounts it deemed "very likely to be domestic" sharing information that 
demonstrated coordinated inauthentic behaviour, as well as participation from national far-right and hate group actors (G7 RRM 2019).

\section{Literature Review: Journalism and Disinformation in a Disrupted Media System}

The quality of citizens' democratic participation is substantially related to the quality of their information environment. As Rollwagen et al. observe, "At least since the time of Walter Lippmann, the quality of news coverage has been linked explicitly to informed public opinion, political agendas and policy making, a relationship whose mechanics continue to be probed and debated" $(2019,462)$. The role that news media play in elections is particularly important, and past research has demonstrated journalists' influence on the agenda or framing of election campaigns, the communication practices of candidates, and voters' opinions (Druckman 2005; McCombs 2014).

Journalism could arguably help respond to disinformation tactics through functions that the news media have traditionally played during election campaigns:

- Agenda-setting role: Focusing public attention on issues of importance, often informed by journalists' sense of news value, rather than letting disinformation actors set the agenda.

- Informational role: Correcting false claims and informing voters of key facts, in order to counteract the spread of false or misleading claims.

- Watchdog role: Holding parties, platforms, and third-party groups to account for violations of laws or expectations, including attempts to mislead the public.

- Convening role: Providing opportunities for citizens to publicly discuss and debate issues, and transmit citizen views to politicians. 
These roles relate closely to what has been termed the journalists" "credo" in Canada, a set of five professional values that have dominated Canadian journalists' self-conceptions for more than two decades: accuracy, disseminating news quickly, giving ordinary people the chance to express their views, investigating government, and providing analysis of complex problems (Rollwagen et al. 2019). These normative commitments influence journalists' selection of what stories to tell, and how to tell them — often analyzed as the "news judgment" or "news values" of journalism (O’Neill and Harcup 2019). Studies of news judgment in practice find that these normative commitments are not the only important considerations for journalists. In election campaigns, news media have been accused of paying inappropriate attention to opinion polls, to powerful political and economic actors rather than citizens, to the spectacle and entertainment value of campaigns rather than their substance, and to the "horse race" dynamic of campaigns rather than policy issues (Patterson 2017; Druckman 2005). Despite these misgivings, there are consistent empirical findings that people who consume professional news media are, on average, better informed and more active in politics than those who do not (Strömbäck and Shehata 2010).

\section{Journalism organizations as antidotes and amplifiers of disinformation}

The journalism sector is arguably well-suited to addressing online disinformation. Indeed, public concerns about disinformation and fake news provide professional journalists with a powerful justification for their continued importance (Egelhofer and Lecheler 2019; Tandoc, Jr., Jenkins, and Craft 2019). However, journalists' capacity to counteract disinformation has been undermined by many of the same forces that have made information systems vulnerable to new disinformation tactics. 
Journalists, particularly investigative journalists at elite news organizations, have played key roles in exposing fake news creators and disinformation actors. For instance, journalists have exposed the Russian IRA (Chen 2015), investigated for-profit fake news operations (Silverman and Alexander 2016), and revealed how social media platforms have facilitated fake news and disinformation campaigns (Cadwalladr 2017). In Canada, prior to the 2019 election, journalists had identified Islamophobic conspiracy theories on social media (Lamoureux 2018; Goldsbie 2018), exposed fake messages that attempted to link LGBTQ activists to the promotion of pedophilia (Lytvynenko 2018), and revealed false information sent via robocalls in the 2011 federal election (Coxon 2014).

However, journalists have also been duped and manipulated in ways that aid disinformation campaigns (Donovan and Friedberg 2019; Molina and Sundar 2019). In particular, journalists have knowingly and unknowingly amplified or disseminated false information. For example, Russia-backed actors and alt-right groups pushed disinformation from relatively fringe sites into broader circulation, often through sympathetic coverage by right-wing talk radio outlets and Fox News (Benkler, Faris, and Roberts 2018). Mainstream and left-leaning news outlets also reported on false or deceptive messages, sometimes to criticize or debunk them. In doing so, these outlets sometimes extended the audience reach and the agenda-setting power of deceptive messages and disinformation campaigns (Benkler, Faris, and Roberts 2018; Phillips 2018; Wardle 2018).

Journalists also amplify the messages of fake personae, including false accounts and bots. For instance, during the 2016 election campaign in the U.S., 32 out of 33 major American news organizations, including NPR and The Washington Post, quoted tweets created by the Russian IRA and treated them as voices of "real Americans" (Lukito et al. 2020). More generally, news 
media have treated bot-amplified topics — including those that are ranked as "trending topics" — as reflecting widespread public concern (Woolley and Guilbeault 2017; Dubois 2019). Finally, as discussed below, journalists have publicized hacked communications and other illegally obtained documents in ways that advanced the aims of disinformation campaign architects. Journalists continue to report on and amplify disinformation for a variety of reasons, including a commitment to free speech, a desire to debunk misinformation, or the need to include "both sides" of a story (Phillips 2018). In other cases, they are not aware of the effects or origins of such information.

As journalism organizations seek to address the challenges posed by online disinformation, they do so in the midst of significant sectoral turmoil. The widespread availability of digital technology has lowered the barriers to entry for non-traditional news sources, while diverting audiences and advertisers from traditional media such as newspapers and broadcasters. Revenue from advertising and subscriptions has plummeted, resulting in major cuts in Canadian newsrooms: between 2008 and 2017, at least 169 local media outlets closed, and the journalism workforce was slashed by about 30\% (Public Policy Forum 2017). These challenges have arrived as social media has ushered in a non-stop news cycle. News organizations therefore struggle to devote the necessary resources for intensive journalistic coverage, fact-checking, analysis, and investigations. At the same time, news organizations globally have been targeted by populist or partisan actors as politically biased, corrupt, and purveyors of "fake news" (Egelhofer and Lecheler 2019). These attacks have accompanied significant decreases of trust in mainstream journalism globally (Newman et al. 2019, 20-21).

Despite these challenges, news outlets in Canada have a significant reach and remain more trusted than social media or other online news sources. Recent surveys show that 
approximately 7 in 10 Canadians trust the news they get through the traditional media, compared with $14 \%$ for social media and $28 \%$ for digital news organizations (RTDNA / Ipsos 2019). The Reuters Institute's 2019 survey found that $66 \%$ of Canadians got their news from television in the past week, and $28 \%$ from print, compared to $50 \%$ who used social media for news (Newman et al. 2019, 125). Canadians are vulnerable to disinformation that is transmitted through the traditional media precisely because they consume and — to a large extent — trust traditional media institutions.

\section{Methodology}

This chapter draws on interviews with more than 30 reporters, editors and producers (but not opinion columnists) at diverse news organizations across Canada. Interviews were conducted in advance of the 2019 election campaign (April-May 2019, 27 interviews), and in the aftermath of the campaign (October-December 2019, 12 interviews). Some journalists were interviewed before and after the campaign. The semi-structured interviews focused on the forms of disinformation that journalists expected, the skills and organizational capacities needed to address disinformation, and how these issues intersect with journalists' role in the protection of election integrity. Interviewees were given the option of having their comments attributed by name, by role (e.g. "politics editor at a national broadcaster") or kept anonymous. Interview transcripts were analyzed to identify journalism practices, organizational practices, and interpretive frames brought to bear by journalists. As per the methodology of Kreiss et al. (2018), our analysis toggled between identifying emergent categories in interview transcripts, and engaging concepts from scholarship on journalism and political disinformation. 
Interviewees were selected to achieve organizational diversity with respect to organization size, audience scope (national or local), geographic location (British Columbia, Ontario, Quebec, Prairie and Maritime provinces), primary medium (print, broadcast, digital) and reporting language (English, French, and Chinese-language outlets). We over-sampled federal politics reporters at national news organizations who had previously covered online disinformation. The aim of these selection criteria was to achieve a diverse set of in-depth perspectives rather than statistical representativeness. ${ }^{2}$ Initial contact with journalists was made by email; in some cases we were re-directed to other reporters, editors or producers at the organization.

Pre-election interviews were conducted with:

- National news organizations and wire services such as $\mathrm{CBC}$, The Canadian Press, The Toronto Star (14 interviewees)

- Local and regional news organizations (seven interviewees)

- Quebec-based news organizations such as Radio-Canada (four interviewees)

- Digital-first organizations such as BuzzFeed News (seven interviewees)

For the post-election interviews, we focused on journalists who had reported significantly on disinformation during the campaign, based on our review of the 2019 election coverage. These organizations included: BuzzFeed News, CBC, The Globe and Mail, Global News (in partnership with Storyful, a social media monitoring agency), Radio-Canada and The Toronto

\footnotetext{
${ }^{2}$ We also ensured that our interviewee sample included a significant proportion of women journalists and journalists of colour. This chapter does not thematize the relationship between journalists' approaches to disinformation and their organization type, gender or racialized status, or whether they report for dominant or ethnic minority audiences. We intend to do so in future work, as research suggests that all these factors influence political news judgment (Lindgren 2014; Tolley 2016).
} 
Star. Interviews were also conducted with individuals not in this list, but whom we cannot name without compromising their request that their identity not be revealed.

\section{What Counts as Disinformation?}

If journalists are to investigate, identify, and respond to disinformation, they need to know what it is. In the lead-up to the 2019 election, Canadian journalists who planned to report on disinformation around the 2019 election tended to conceive of it as a set of relatively novel digital techniques, used by both conventional and new types of political actors, and which required journalists to monitor relatively new information spaces. The vast majority distinguished "disinformation" (intentionally misleading, false, or manipulative content) from "misinformation" (false or misleading claims spread unintentionally, or for purposes other than manipulation such as satire) (see Wardle and Derakhshan 2017).

However, our interviews reveal significant fuzziness or disagreement among journalists when it comes to disinformation tactics that don't fit the model of Russian interference in the U.S. election. As one editor put it, "There is a lack of clarity on the definition of dis/misinformation ... and [how these relate to] the rumours we hear or see on social media every day." And James McCarten of The Canadian Press, who was the acting Ottawa bureau chief during the 2019 election, observed, "We're still discovering the boundaries of this particular universe, and it seems quite limitless. We're all learning as we go. Right now it's hard to say, 'these are the parameters of the problem, so these are the potential solutions we're going to apply."” 
New digital techniques

Interviewees anticipated that automated (bot) or semi-automated (cyborg) false accounts could be deployed to spread disinformation. More broadly, some interviewees were prepared to confront the viral spread of false or deceptive claims and stories on social media platforms. In addition to using fake accounts, these could be promoted by actors gaming search algorithms, or through "brigading" campaigns coordinated on message boards such as 4Chan and 8Chan. Journalists at smaller local and regional news outlets tended to assume they would not encounter these tactics because they would more likely come at a national scale, though there is evidence that foreign states and other actors do create false accounts to advance perspectives in smaller communities (e.g. Bastos and Farkas 2019).

Many expected to encounter manipulated or misleading images and video during the election campaign. These could include simple edits, such as the slowed-down video of U.S. politician Nancy Pelosi that spread in 2019, or images that circulate with false or misleading text about what the image depicts or implies. Journalists were also aware of the spread of "deepfake" video technologies, which use artificial intelligence to make someone appear to say or do something they never did (Paris and Donovan 2019), though few expected they would be used to real effect in the 2019 campaign.

Finally, most interviewees expected there would be leaks of documents or communications from candidates or political parties, perhaps acquired through cyber-security breaches, that would be made public during the election campaign. As we discuss below, journalists had encountered this tactic before the 2019 campaign, and there was significant debate and disagreement regarding when and how anonymous leaks should be covered. 


\section{New or digitally enabled actors}

While these techniques may be used by different types of actors, including candidates and political parties, journalists were particularly focused on foreign states, transnational movements and trolling networks, and hyper-partisan organizations in Canada.

Ahead of the election, journalists held competing views about the likelihood of statesponsored disinformation operations. Some suggested Canada is of little geo-strategic importance and would be ignored. Others disagreed, such as Alex Boutilier, a national security reporter at the The Toronto Star:

Since 2016, every major Western ally that we have has faced serious incidents involving either hacking or influence campaigns or general tomfoolery, trying to influence the outcome of an electoral event or simply create chaos .... Canada is a G7 nation, we are a Five Eyes partner, and there is no reason to suspect that we will not face the same kinds of issues.

Journalists at multiple organizations suggested that state actors might use new disinformation tactics that would be hard to detect, and that journalists would depend on investigations by national security agencies and social media companies. As a result, explained a senior editor at a national newspaper, "what you're doing is covering these institutions, and your ability to hold them to account or challenge their narrative is very limited."

Journalists also raised the risk of over-attributing unusual political activity to state actors. "You can end up being alarmist about it," a national newspaper editor said. "Because of 
narratives around the 2016 U.S. election, everyone is ready and eager to call out Moscow and Beijing for meddling."

In addition to foreign states, journalists were looking for false claims and trolling operations by transnational movements, including white supremacist groups. Indeed, reporters with BuzzFeed News and The Toronto Star covered these groups' online presence prior to the election campaign (Silverman, Boutilier, et al. 2019; Silverman, Vo, and Lytvynenko 2018).

Journalists also noted the rise of online, hyper-partisan organizations in Canada and suggested that they could contribute false and deceptive claims during elections. For instance, in the lead-up to the 2018 Ontario provincial election, a third-party political group called Ontario Proud gained notoriety for running a sophisticated social media campaign supporting the Progressive Conservatives, who won in a landslide. Adam Radwanski, a political reporter at The Globe and Mail, said that hyper-partisan messages are not necessarily "disinformation," and have long been produced by partisan and third-party organizations, but he was struck by the impact of Ontario Proud's messaging, particularly on divisive issues such as immigration. Following the Ontario election, there were concerns that other groups would similarly run sophisticated online campaigns with hyper-partisan and occasionally misleading messaging. In fact, Ontario Proud's founder created a nationwide group called Canada Proud, and other regional networks of third-party groups sprang up ahead of the federal election (Silverman, Lytvynenko, et al. 2019).

Journalists also identified highly partisan, quasi-journalism sites as potential sources of misleading content, and certainly as contributing to a more partisan information environment. The editor of a major Albertan newspaper, describing the 2019 provincial election in Alberta, observed that organizations such as Rebel Media and PressProgress, and Twitter feeds of 
important partisan influencers, complicated electoral reporting by regularly leaking material or circulating polarizing stories: "We were continually chasing after these pieces, because they were too prominent on social media to simply ignore. The fact-checking exercises we went through to determine what was a real story was a big daily endeavour." The role of highly partisan, quasi-journalism outlets became a controversial issue during the 2019 election campaign. Rebel Media and the True North Centre for Public Policy won a court order to have the Leaders' Debate Commission accredit their employees as journalists, which the Commission had initially refused to do (Loriggio 2019).

In general, interviewees claimed that these hyper-partisan Canadian organizations were not disinformation actors on par with antagonistic states. However, several journalists did point out that hyper-partisan actors sometimes used similar techniques as foreign adversaries or worked toward the same goal of heightening social divisions.

New spaces

Canadian journalists have for years used social media platforms to gather news and find potential sources. The focus on disinformation campaigns in elections prompted a more general concern with the quality of information on social networks, and a desire to identify false claims or false beliefs circulating there before they had a broader impact. In this sense, journalists are not functioning as gatekeepers over what comes into the information system, but rather as monitors trying to point out the most problematic communication that is circulating. As Radwanski put it, "We are trying to gain a better handle on what is out there, what's behind certain unreliable-looking news that's coming through right now. There's an effort to at least understand the landscape better." 
This role as internet monitor is extremely daunting for journalists, and interviewees held different positions on whether that role was appropriate or even feasible for news outlets. As a senior producer at a national broadcaster put it: "It's not just Facebook and Twitter; it's WeChat and YouTube ... then there is 4Chan and Gab and, oh my god, it's endless. A big part of this is where to focus .... We are putting significant resources into this, but we could put in an endless amount and still leave some bases uncovered."

Journalists who report on disinformation often seek to track potentially false or misleading content as it spreads online, so that they may verify or debunk a claim or investigate the actors behind it. Journalists are particularly interested in identifying problematic content that is likely to reach a large audience.

This is difficult for several reasons. Even journalists trained in specialized techniques may struggle to identify viral material on Twitter or public Facebook pages; this becomes much harder in closed spaces such as WhatsApp or private Facebook Groups. Content shared in a "closed" or "secret" Group is only visible to members of the group, potentially enabling disinformation to circulate and disinformation actors to coordinate without detection. "Other platforms like Reddit, 4chan and Discord, an encrypted chat platform, have hosted this kind of activity for years, but Facebook brings it to a broader, less internet-savvy audience" (MacLellan 2018). Only a few interviewees were significantly engaged in tracking the activities of private Groups, which can be very labour intensive, and may require disguising one's identity (which is discouraged by many journalism organizations except in rare situations). These challenges are increasing, according to Jeff Yates, a Radio-Canada journalist who focuses on disinformation: 
A lot of false stories are now being spread in dark spaces, making it harder to track, harder to know who saw it, and harder to hold anyone accountable ... I think that bad actors understand social media better than most journalists. They know how to push buttons to get stuff to go viral, and we really don't know how to stop that.

These and other obstacles are faced by journalists investigating social media use in diaspora communities. WhatsApp is a popular digital platform for some diaspora groups in Canada, and it has been a major vector for political disinformation in countries where it is popular, such as Brazil and India. Several interviewees highlighted the importance of WeChat, both as a popular platform for Mandarin and Cantonese conversations, and as a China-based company subject to government influence. They stated that content on WeChat, including stories by their own news organizations on topics such as Huawei executive Meng Wanzhou and the U.S.-China trade war, were sometimes censored by the platform. Journalists were also concerned about Chinese government surveillance of messaging on WeChat, and one interviewee declared, "I would never send someone a message on WeChat that I didn't want the Chinese government to hear."

In sum, while interviewees agreed on clear cases of disinformation such as forms of Russian interference in the 2016 U.S. election, there were differences in judgment with respect to some tactics and actors. There were also different conceptions of the roles or capacities of journalists across diverse social media spaces. These differences in perspective become clearer when discussing concrete cases that occurred — or might have occurred — in the 2019 election campaign. 


\section{Case 1: \#TrudeauMustGo and Challenges of Attribution}

Journalists expected to see bots used during the election campaign to amplify messages, or to harass candidates and journalists themselves. However, many were unsure whether their newsrooms would have the capacity to identify bot networks or determine who was behind them. The challenges of doing so became apparent in reporting on the \#TrudeauMustGo hashtag, which became prominent during the election campaign.

There is extensive evidence of large-scale bot activity in the U.S. 2016 election, and most journalists regularly encounter suspicious accounts that appear not be real people — such as recently created Twitter accounts with few followers and no profile picture. However, some interviewees expressed concern that journalists are too quick to dismiss new, prolific and critical accounts as bots, which puts them at risk of disregarding legitimate public concerns and comments. A journalist at an online news organization said: "In general, 'bot' is just a bad word people use to describe lots of problematic accounts." The Globe and Mail's Radwanski suggested that journalists may too quickly think, "Aha, this is a fake account or a bot or Russian or whatever." He continued, "I'm not sure we're actually trained to figure that out .... [We need] to strike the right balance between healthy skepticism without being dismissive."

This tendency to over-identify questionable accounts as bots may have contributed to the confusion around the \#TrudeauMustGo hashtag and whether it was amplified by bots, which was discussed by journalists and researchers in the weeks and months leading up to the election (Orr 2019; Jones 2019). About a week before the election, digital researcher Marc Owen Jones posted an analysis on Twitter examining 12,000 unique accounts that had posted on the \#TrudeauMustGo hashtag. Jones wrote that that about $10 \%$ of Twitter accounts using the hashtag included MAGA (short for Donald Trump's “Make America Great Again” slogan) in their 
profile bios. Users tweeting on the hashtag also displayed clustering behaviour (i.e. retweeting similar groups of users) and tweeted at disproportionately high volumes. "Given everything I have seen I would say with a lot of confidence that this is just part of the long running rightwing, pro-Trump influence campaign active on issues as diverse as Iran, Brexit and climate change denial," Jones tweeted (2019).

In response to Jones' tweets, researchers with the Digital Democracy Project, a civil society partnership tracking the Canadian media environment leading up to the election, analyzed a sample of 70,000 accounts posting on \#TrudeauMustGo and other anti-Trudeau hashtags. ${ }^{3}$ They found a similar percentage of accounts with MAGA in their bios; however, closer analysis showed that the accounts tended to follow rank-and-file candidates of the Conservative Party and right-wing populist People's Party of Canada, rather than just candidates with a high national or international profile, and posted on primarily Canadian issues, which would suggest a familiarity with Canadian politics beyond international headlines (Digital Democracy Project 2019). Further analysis of the 6,062 most active Twitter accounts with MAGA in their bios (out of a total of 46,851) determined that these accounts were slightly more likely to be automated than the general population of users tweeting about the election: $2 \%$ of MAGA accounts were likely automated, compared to $1 \%$ of general accounts (Digital Democracy Project 2020, 99-101). However, "neither automated nor manual analysis uncovered evidence of co-ordinated behaviour that we would label election manipulation or interference" (ibid, 4).

\footnotetext{
${ }^{3}$ MacLellan, one of this chapter's co-authors, worked with the Digital Democracy Project in a news media liaison and editorial capacity.
} 
This case illustrates two broader problems. The first is the common challenge of attributing online activity, because identities can easily be faked or masked. That question may be particularly important in the context of elections, because false claims have very different political and even legal significance if they come from a candidate or political party, from a foreign state actor, or from misinformed citizens. And as we note below, assessing the identity and motivation of leaked information is essential if journalists are to be less vulnerable to manipulation by leakers.

This case also highlights the broader problem that newsrooms may lack the technical skills needed to identify disinformation tactics, and may be too quick to report on claims made by outside experts — particularly if they make a for a good story.

\section{Case 2: Justin Trudeau's "Sex Scandal" and Challenges of Countering vs. Amplifying Disinformation}

When journalists identify possible disinformation, they often face difficult questions about whether and how to report on it. Multiple interviewees told us that these questions were more challenging than the work of fact-checking claims. Decisions to publicize false or misleading messages may put different journalistic roles in tension. To play their "informational role," journalists may wish to debunk false claims and publicize accurate ones. To play their "watchdog role," they may wish to publicly accuse individuals or organizations who are responsible for those claims — but with disinformation on social media, it is often very difficult to identify who is responsible for creating or propagating content. Finally, to play a productive "agenda-setting role" — and keep attention on substantive issues in an election campaign — they may wish to remain silent about false and misleading claims, because research and journalists' 
experience suggest that even critical attention to a message may amplify its spread or advance its creator's aims (Donovan and boyd 2019; Molina and Sundar 2019; Wardle 2018).

Experts and journalists are increasingly aware that attempts to correct false claims may instead promote awareness or recollection of the false claims. However, recent research has cast doubt on the importance of the so-called "backfire effect" - the possibility that a person's belief in a false claim may be deepened by encountering a correction (Wood and Porter 2019; Nyhan et al. 2019). Moreover, researchers have found that stories intended to correct false claims and misperceptions have very different effectiveness, depending on factors including their form, timing, and audience (Ibid).

Even if stories that address false claims do not promote belief in them, they can displace attention from more important discussions in an election. A francophone reporter, for instance, described how an allegation about a candidate can start moving quickly on social media, perhaps after being retweeted by a few influencer accounts, "and now I'm in a position where I have to fact-check it, find the original source, address it ... And all this emphasis on a false statement, and then the corrections of it, means people don't talk about real issues in depth."

Journalists have long recognized that the public good may be better served by refraining from publicizing certain actions, events, and actors. For instance, journalists tend not to cover suicides, kidnappings, or bomb threats, out of concern that doing so will inspire copycat activities or advance the aims of their perpetrators (Donovan and boyd 2019; see, for instance, sections on Hoaxes and Suicides in "Torstar Journalistic Standards Guide" 2018). Experts and analysts have recommended that similar considerations be brought to bear with respect to forms of online disinformation. Similarly, experts and journalists have increasingly considered the 
tactic of "strategic silence" with respect to the activities or messages of hate groups to avoid driving greater attention to online content that may aid recruitment (Donovan and boyd 2019). Many journalists said their main response to disinformation is to just keep doing good journalism, and not fall for false stories or salacious rumours. "In terms of allegations, accusations, false information, social media has taken them to new heights, but nevertheless it's always about the journalistic question: Is this really something we need to become involved with?" explained an editor overseeing many small local news outlets. "Whether rumours are in the bar or on social media platforms, are they serious or are they junk?"

However, interviewees who regularly investigate the spread of misleading claims on social media have developed more detailed rules of thumb. Journalists considered factors such as how many people had seen it, if a prominent person had repeated it, if it concerned a matter of significant public interest, or if it was known to have been spread by a foreign state actor. In general, the journalists we spoke to said such decisions would be made after discussions between the reporter(s) working on the story and senior editors, relying on their news judgment to weigh the public interest of revealing the information against the possible harms of amplifying a disinformation campaign. "There was no clear red line like, 'Well, once something gets 100,000 shares, we have to talk about it,"” said Jeff Semple, a Global News reporter focusing on disinformation.

Kaleigh Rogers, who reported on disinformation for the $\mathrm{CBC}$ during the election campaign, illustrated how such assessments informed an article on concerns about voter fraud (Rogers and Bellemare 2019). She explained: 
Someone posted on Facebook that voter information cards were sent to foreign exchange students, and this was being used as proof that non-citizens would be voting. We did some basic reporting and thought it hadn't gone that far and we decided not to publish a story on it. Later we found more evidence of people sharing it and other disinformation around voter fraud ...We decided to blend it all into one story, including that initial post. So that's where something shifted from not being significant enough to where we could see a wider trend that it was playing into.

\section{Trudeau's "Sex Scandal" and The Buffalo Chronicle}

Questions about whether and how to report on false and misleading information were most acute in what was arguably the most successful disinformation campaign of the election: rumour and innuendo about past sexual impropriety by the incumbent Liberal prime minister, primarily driven by the U.S.-based The Buffalo Chronicle site.

In the weeks leading up to the election, rumours circulated online that Trudeau was fired from a Vancouver private school for sexual impropriety, and that The Globe and Mail was prevented from running a story about it by a court injunction. At a campaign event, a reporter for The Globe and Mail asked Trudeau about "unfounded rumours" surrounding his departure from the West Point Grey Academy, and whether he signed a non-disclosure agreement with the school; Trudeau said no (Baudoin-Laarman 2019). In the following hours and days, speculation about the rumours circulated throughout Canadian political Twitter accounts, culminating in the Conservative Party issuing a news release on Oct. 7 questioning why Trudeau left the school (ibid.) Later that day, The Buffalo Chronicle, which had previously published baseless stories about Canadian politics, published an unsigned story alleging that Trudeau was negotiating with 
a former student to keep the scandal from becoming public. The story spread to an estimated 24.6 million people through Facebook, Twitter and Reddit, according to data from social media tracking tool CrowdTangle (McIntosh 2019).

Rumours of a sex scandal involving Trudeau and the private school had circulated among the journalism community for weeks before The Buffalo Chronicle story was published (Oved 2019). But once The Buffalo Chronicle published the rumours as a news story, and once the rumour was alluded to by political operatives and a Conservative Party press release (Digital Democracy Project 2020, 109-15), journalists were forced to grapple with an important question: even if your own reporting and news judgment have not convinced you that a story is worth covering, at what point does it become too big to ignore?

In the case of The Buffalo Chronicle, some reporting differed from the binary alternatives of either publishing or staying silent, such as reporting on elements of a potential disinformation campaign rather than the narrative it promotes. For example, the Agence France-Presse factchecking unit ran a story debunking the rumour that an injunction had been issued against The Globe and Mail to prevent it from running a story about the scandal rather than delving into the details of the alleged scandal itself (Baudoin-Laarman 2019). Joint reporting by The Toronto Star and BuzzFeed led to investigative pieces on The Buffalo Chronicle's shady publishing practices and how it skirted the government's new anti-disinformation policies (Silverman, Lytvynenko, and Oved 2019).

Reflecting on this case, Jane Lytvynenko of BuzzFeed News observed:

I think that's what the ultimate takeaway is: that people in the U.S. can very easily cross the border using the internet and target Canada with disinformation. And Canadians 
may fall for it sometimes ... because they don't know what the publication is, they don't understand its reputation, they don't have enough information to make an informed decision. Whether there will be more Buffalo Chronicles in future elections remains to be seen.

\section{Case 3: Responding to Leaks: The Challenge of Not Getting Conned}

Many journalists expected document leaks during the election campaign, whether in the form of public data dumps of hacked communications as in the U.S. election, or the more common sharing of select computer files or paper records. As one journalist stated, "I was very surprised during this campaign by the notable absence of leaked documents. I expected that would be the major issue that we'd all be chewing over in newsrooms: what do with legitimately newsworthy information of dubious provenance landing anonymously in our laps?"

Journalists expected these leaks in part because they had happened before in Canada. For instance, several months before the 2015 federal election, hackers claiming to belong to the loosely organized Anonymous collective released confidential government documents that revealed the number of foreign stations of the Canadian Security Intelligence Service, financial information about Canadian diplomatic buildings in the United Kingdom, and other information. An Anonymous spokesperson told the National Post that the release of the documents, accompanied by rhetorical videos, was aimed at influencing the election (Humphreys 2015). These documents did not get significant attention from mainstream media during the election season, perhaps because they did not include "smoking gun" revelations of problematic behavior by elected officials (McKelvey, Côté, and Raynauld 2018). 
Leaks have been characterized by Wardle and Derakhshan (2017) as a form of "malinformation," or true information that is strategically released with the purpose of harming its targets. The clearest recent cases are the leaks of hacked communications from the Democratic Party in the U.S. 2016 election, and from Emmanuel Macron's campaign team in the 2017 presidential election in France. Journalists have been criticized for publishing hacked communications and other illegally obtained documents in ways that advanced the aims of disinformation actors in elections (Zelinsky 2017). For instance, WikiLeaks released the private emails of John Podesta, the head of the Clinton campaign, in drips and drops during the final weeks of the 2016 U.S. election, steering the news cycle from topics that may have been more substantive or harmful to the Trump campaign (Lubben 2017). This has led to calls for journalists to be guided by a "professional presumption" against publishing information obtained through illegal cyber activity, particularly if this activity is likely to interfere in democratic processes (Zelinsky 2017, 305).

The journalists we interviewed were well aware of the potential strategic use of data dumps and other leaks. Many likened the issue to the longstanding discussions among journalists about how to treat the proverbial "brown envelopes" containing anonymously leaked documents that are sometimes sent to newsrooms. Many stated that similar vetting procedures would be applied to leaked documents regardless of how they were transmitted. Paul Berton, the editor-inchief of the Hamilton Spectator, said that occasionally, "there have been great stories in those brown paper envelopes which we haven't done, because the motivation of the sender is suspicious or malign."

Regardless of whether journalists knew the identity or motivation of the sender, they would take steps to verify the accuracy of the contents before publicizing them. Another 
consideration is the extent to which it was in the public interest to have the contents revealed. As one national newspaper reporter explained, he wouldn't want his organization to publicize a leak "just for a bit of salacious gossip," but if the leak "exposed legitimate corruption and you could verify it, I think you would be hard pressed not to.”

Our interviewees observed that while Canadian newsrooms had considered these issues, and developed some guidelines, clearer discussions within journalism organizations and with the larger public were necessary. One commonly voiced concern was that after one news organization publicizes a leak, other outlets may abandon their usual concerns about doing so. One reporter observed:

My paper can have all the standards in the world and... [consider] the interests of the country and our readers. But the second that the Toronto Sun runs something, it becomes a news story. That, to me, is the more difficult question in this: How we handle something once it's in the mainstream ecosystem, how we cover that story in a responsible way?

He concluded, "That's something that newsrooms across the country have to talk about before we're in the heat of an election campaign. Because the heat of an election campaign is no time to be making standards and principles."

\section{Conclusion: Updating News Judgment and Skillsets for the Next Election}

This chapter reveals some of the complex interconnections between evolving digital technologies and cyber-threats to electoral integrity. The journalists we interviewed saw 
themselves as being on the frontlines of efforts to counteract disinformation campaigns, as well as making the public aware of other cyber-threats to electoral integrity such as hacking operations targeting political parties. When it came to identifying disinformation and its threat to electoral integrity, journalists highlighted novel techniques of digital media manipulation and foreign interference, but they placed the increased danger of disinformation in a broader context of upheaval in the media system. That upheaval includes the increasing prominence of quasijournalistic or hyper-partisan organizations online, and the expansion of online spaces where disinformation actors can organize or can spread misleading claims. Furthermore, the rise of social media platforms has undermined journalism's gatekeeping role and — to an extent — its economic viability.

When deciding how they should respond to disinformation, many of the journalists we interviewed saw the issue of disinformation from two perspectives: as a technical challenge requiring journalism organizations to develop new capacities, and as an ethical and professional challenge to address forces that are undermining the role and reputation of journalism. In their attempts to address disinformation, journalists thus also strove to update their role as trusted, if diminished, gatekeepers of information. These dual aims were apparent in our journalists' debates and personal reflections, such as how to ethically report on hack and leak operations, or how much attention to give to sensational claims about bots or salacious rumours.

This chapter's findings contribute to growing scholarship on the relationship between disinformation and journalism (Donovan and boyd 2019; Donovan and Friedberg 2019; Phillips 2018; Wardle and Derakhshan 2017). It helps address two gaps in that scholarship: the insufficient attention to the practices and reflexive perspectives of journalists themselves, and the overwhelming focus on the U.S. This study can thus provide insights for comparative research 
that seeks to understand factors that influence the vulnerability of different media systems to disinformation generally, and election-based disinformation campaigns specifically (Humprecht, Esser, and Van Aelst 2020). Finally, this chapter helps illuminate the role that journalism organizations play in extending or counteracting the reach of disinformation in the Canadian public, as others have investigated (Digital Democracy Project 2020; Bridgman et al. 2020).

The challenges that journalists faced in addressing disinformation in the 2019 election campaign - including how to evaluate the reach of bots and how to respond to viral unsubstantiated rumours - will likely recur in future elections. It's likely that there will be new tactics used, including new forms of synthetic media, masked identities, and strategic coordination in dark or private spaces online. It is also likely that misleading and divisive claims will be leveraged by conventional political actors, from candidates to interest groups. And, regrettably, journalism organizations will likely still have too few technical and human resources to tackle an increasingly complex information system.

Journalists' experiences in the 2019 election suggest several broad lessons to prepare for the future. First, newsrooms will need to update skillsets if they hope to be able to identify and investigate these tactics and the actors responsible. While journalists may be well versed in critically evaluating and verifying traditional information sources, they do not always have the technical skills to detect disinformation or influence campaigns that surface online. Such skills would include identifying falsified photos or documents, detecting bot accounts, and navigating platforms such as 4chan or Discord that are often used to plot disinformation campaigns. Specialist organizations have begun to offer training on these skills. However, given the complexity and evolving nature of disinformation tactics, it's inevitable that journalists will frequently need to draw on outside expertise. These may sometimes come from specialist digital 
media organizations, such as BuzzFeed News (which partnered with The Toronto Star) or Storyful (which partnered with Global News). Expertise may also come from university-based researchers, analysts at technology companies, or Canada's intelligence agencies. Journalists will need to cultivate healthy sourcing relationships with these different types of experts, which will frequently include elements of trust and skepticism.

Second, reporting on disinformation will continue to involve significant amounts of ambiguity. This begins with the fuzziness about what disinformation is. Do hyper-partisan or misleading statements count as disinformation only when made by foreign actors, or also when amplified by political parties and partisan "influencers" in Canada? Does a misleading photo or video count as political commentary or satire, even if many people who consume and share it do not know that it is misleading? When should leaked documents be publicized, and how can this be done without allowing the leaker to unduly influence the public conversation at critical junctures during an election campaign? These and other questions put pressure on journalists' news judgment. Not only do journalism organizations need to cultivate responsible news judgment, and institute policies to support it, they also need to engage the wider public in conversations on the issue.

These questions of judgment about what to treat as disinformation, and what to ignore or call out, become more difficult when candidates and political parties share misleading information. Indeed, many journalists interviewed after the election declared that candidates and parties were arguably the most prominent disinformation actors. A politics editor for a national news outlet observed: "It feels like instead of walking a line between spin and actual falsehoods ... [politicians] don't seem as concerned about staying on the right side of the line.” 
Third, while journalists play a weaker — though still important — gatekeeping function in the information system, they may play an increasingly important role in informing the public about other actors' strategic communication during elections. To do so, journalists need to be able to investigate and critically assess the potential impact of misinformation and disinformation. They also need to better understand their own capacities to counteract or amplify those impacts. Here, too, journalists may need to deepen their working relationships with outside experts, who can help evaluate the impacts of different reporting strategies on public understanding and on disinformation effects. Reflecting on his newsroom's partnership with Storyful, Jeff Semple of Global News said: "I think the nice thing that the federal election did, for us anyway, is that now, even though the election is over, we in this newsroom have developed a new set of skills and contacts and tools, and are still keeping an eye on this space." But again, the cultivation of responsible news judgment, through internal and public dialogue, will be key. Journalists in a disrupted information ecosystem continue to play gatekeeping and agenda-setting roles, but their impact and legitimacy are being questioned in every major election.

\section{References}

Bastos, Marco, and Johan Farkas. 2019. “'Donald Trump Is My President!': The Internet Research Agency Propaganda Machine.” Social Media + Society 5 (3): 1-13. https://doi.org/10.1177/2056305119865466.

Baudoin-Laarman, Louis. 2019. "Canada's National Newspaper Was Not Barred from Publishing a Scandal Involving PM Trudeau." AFP Fact Check, October 9, 2019. https://factcheck.afp.com/canadas-national-newspaper-was-not-barred-publishingscandal-involving-pm-trudeau. 
Bayer, Judit, Natalija Bitiukova, Petra Bard, Judit Szakács, Alberto Alemanno, and Erik Uszkiewicz. 2019. "Disinformation and Propaganda - Impact on the Functioning of the Rule of Law in the EU and Its Member States.” Brussels: Policy Department for Citizens' Rights and Constitutional Affairs, European Parliament. http://www.europarl.europa.eu/RegData/etudes/STUD/2019/608864/IPOL_STU(2019)60 8864_EN.pdf.

Benkler, Yochai, Robert Faris, and Hal Roberts. 2018. Network Propaganda: Manipulation, Disinformation, and Radicalization in American Politics. Oxford: Oxford University Press.

Boutilier, Alex. 2018. “CSIS Sees 'Significant' Jump in Far-Right Activity Online.” The Toronto Star, October 8, 2018. https://www.thestar.com/news/canada/2018/10/05/csis-seessignificant-jump-in-far-right-activity-online.html.

Bradshaw, Samantha, and Philip N. Howard. 2018. "Challenging Truth and Trust: A Global Inventory of Organized Social Media Manipulation.” Working Paper. Oxford: Project on Computational Propaganda. https://comprop.oii.ox.ac.uk/research/cybertroops2018/.

Bridgman, Aengus, Eric Merkley, Peter John Loewen, Taylor Owen, Derek Ruths, Lisa Teichmann, and Oleg Zhilin. 2020. "The Causes and Consequences of COVID-19 Misperceptions: Understanding the Role of News and Social Media." Harvard Kennedy School Misinformation Review 1 (3). https://doi.org/10.37016/mr-2020-028.

Brin, Colette. 2018. “Canada.” Digital News Report (blog). 2018. http://www.digitalnewsreport.org/survey/2018/canada-2018/.

Cadwalladr, Carole. 2017. "The Great British Brexit Robbery: How Our Democracy Was Hijacked." The Guardian, May 7, 2017. https://www.theguardian.com/technology/2017/may/07/the-great-british-brexit-robberyhijacked-democracy.

Chen, Adrian. 2015. "The Agency.” The New York Times, 2015.

Communications Security Establishment. 2017. “Cyber Threats to Canada's Democratic Process." Government of Canada. https://www.cse-cst.gc.ca/sites/default/files/cse-cyberthreat-assessment-e.pdf. 
_ 2019. "2019 Update: Cyber Threats to Canada’s Democratic Process.” Ottawa:

Government of Canada. https://cyber.gc.ca/sites/default/files/publications/tdp-2019report_e.pdf.

Coxon, Lisa. 2014. "How Glen McGregor and Stephen Maher Broke the Robocalls Scandal." The Ryerson School of Journalism, March 28, 2014. https://rrj.ca/how-glen-mcgregorand-stephen-maher-broke-the-robocalls-scandal/.

Deeks, Ashley, Sabrina McCubbin, and Cody M. Poplin. 2017. “Addressing Russian Influence: What Can We Learn From U.S. Cold War Counter-Propaganda Efforts?" Lawfare, October 25, 2017. https://www.lawfareblog.com/addressing-russian-influence-what-canwe-learn-us-cold-war-counter-propaganda-efforts.

Digital Democracy Project. 2020. "Lessons in Resilience: Canada's Digital Media Ecosystem and the 2019 Election." Ottawa and Montreal: Public Policy Forum and the Max Bell School of Public Policy, McGill University. https://ppforum.ca/articles/lessons-inresilience-canadas-digital-media-ecosystem-and-the-2019-election/.

Donovan, Joan, and danah boyd. 2019. "Stop the Presses? Moving From Strategic Silence to Strategic Amplification in a Networked Media Ecosystem." American Behavioral Scientist. https://doi.org/10.1177/0002764219878229.

Donovan, Joan, and Brian Friedberg. 2019. "Source Hacking: Media Manipulation in Practice." New York: Data \& Society Research Institute. https://datasociety.net/output/sourcehacking-media-manipulation-in-practice/.

Druckman, James N. 2005. "Media Matter: How Newspapers and Television News Cover Campaigns and Influence Voters." Political Communication 22 (4): 463-81. https://doi.org/10.1080/10584600500311394.

Dubois, Elizabeth. 2019. "Manipulation Is a Serious Risk for Journalists Using Social Media." Policy Options, September 3, 2019. https://policyoptions.irpp.org/magazines/september2019/manipulation-is-a-serious-risk-for-journalists-using-social-media/.

Edelman Intelligence. 2018. "2018 Edelman Trust Barometer." https://www.edelman.com/sites/g/files/aatuss191/files/201810/2018_Edelman_TrustBarometer_Executive_Summary_Jan.pdf. 
Egelhofer, Jana Laura, and Sophie Lecheler. 2019. "Fake News as a Two-Dimensional Phenomenon: A Framework and Research Agenda." Annals of the International Communication Association 43 (2): 97-116. https://doi.org/10.1080/23808985.2019.1602782.

G7 RRM. 2019. “Alberta Election Analysis.” G7 Rapid Response Mechanism, Global Affairs Canada. https://www.international.gc.ca/gac-amc/publications/rrmmrr/alberta_elections.aspx?lang=eng.

Goldsbie, Jonathan. 2018. "How The Far Right Spun The Toronto Van Attack As Islamic Terrorism.” CanadaLand. April 24, 2018. http://www.canadalandshow.com/far-rightspun-the-toronto-van-attack-as-islamic-terrorism/.

Government of Canada. 2019. "Safeguarding Elections.” Backgrounders. Democratic Institutions, Government of Canada. February 5, 2019. https://www.canada.ca/en/democratic-institutions/news/2019/01/safeguardingelections.html.

Humphreys, Adrian. 2015. “Anonymous Leaks Another High-Level Federal Document as Part of Vendetta against Government." National Post, September 26, 2015. http://news.nationalpost.com/news/canada/anonymous-leaks-another-high-level-federaldocument-as-part-of-vendetta-against-government.

Humprecht, Edda, Frank Esser, and Peter Van Aelst. 2020. "Resilience to Online Disinformation: A Framework for Cross-National Comparative Research.” The International Journal of Press/Politics 25 (3): 493-516. https://doi.org/10.1177/1940161219900126.

Jones, Marc Owen. 2019. “Twitter Thread on the 'Trudeau Must Go' Hashtag." Twitter (blog). September 6, 2019. https://twitter.com/marcowenjones/status/1170046922381508609.

Kreiss, Daniel, Regina G. Lawrence, and Shannon C. McGregor. 2018. "In Their Own Words: Political Practitioner Accounts of Candidates, Audiences, Affordances, Genres, and Timing in Strategic Social Media Use.” Political Communication 35 (1): 8-31. https://doi.org/10.1080/10584609.2017.1334727. 
Lamoureux, Mack. 2018. "Here Are the Far-Right Conspiracists the Quebec City Mosque Shooter Followed.” Vice. April 16, 2018. https://www.vice.com/en_ca/article/ywxeyg/here-are-the-far-right-conspiracists-thequebec-city-mosque-shooter-followed.

Lindgren, April. 2014. “Toronto-Area Ethnic Newspapers and Canada's 2011 Federal Election: An Investigation of Content, Focus and Partisanship." Canadian Journal of Political Science/Revue Canadienne de Science Politique 47 (4): 667-96.

Loriggio, Paola. 2019. "Right-Wing Outlets Win Legal Battle to Attend the Leaders' Debate." CBC News, October 7, 2019. https://www.cbc.ca/news/politics/rebel-media-true-northfederal-election-debate-2019-1.5312172.

Lubben, Alex. 2017. “This One Insane Day Changed the Course of U.S. Politics Forever.” Vice News. June 23, 2017. https://news.vice.com/story/this-one-insane-day-changed-thecourse-of-u-s-politics-forever.

Lukito, Josephine, Jiyoun Suk, Yini Zhang, Larissa Doroshenko, Sang Jung Kim, Min-Hsin Su, Yiping Xia, Deen Freelon, and Chris Wells. 2020. “The Wolves in Sheep's Clothing: How Russia’s Internet Research Agency Tweets Appeared in U.S. News as Vox Populi:” The International Journal of Press/Politics 25 (2): 196-216. https://doi.org/10.1177/1940161219895215.

Lytvynenko, Jane. 2018. "Far-Right Trolls Are Falsely Saying LGBT Activists Want Pedophilia Accepted.” BuzzFeed News. August 3, 2018. https://www.buzzfeednews.com/article/janelytvynenko/far-right-trolls-lgbt-pedophiliahoax.

MacLellan, Stephanie. 2018. "Digital Security Risks to Follow in 2019." Centre for International Governance Innovation (blog). December 31, 2018. https://www.cigionline.org/articles/digital-security-risks-follow-2019.

McCombs, Maxwell. 2014. Setting the Agenda: Mass Media and Public Opinion. 2nd ed. Cambridge, UK: Polity Press.

McIntosh, Emma. 2019. “A Fake Justin Trudeau Sex Scandal Went Viral. Canada’s ElectionIntegrity Law Can’t Stop It.” National Observer, October 10, 2019. 
https://www.nationalobserver.com/2019/10/10/news/fake-justin-trudeau-sex-scandalwent-viral-canadas-election-integrity-law-cant-stop.

McKay, Spencer, and Chris Tenove. 2020. "Disinformation as a Threat to Deliberative Democracy." Political Research Quarterly 0 (0): 1-15. https://doi.org/10.1177/1065912920938143.

McKelvey, Fenwick, Marianne Côté, and Vincent Raynauld. 2018. "Scandals and Screenshots: Social Media Elites in Canadian Politics." In Political Elites in Canada: Power and Influence in Instantaneous Times, edited by Alex Marland, Thierry Giasson, and Andrea Lawlor, 204-22. Vancouver: UBC Press.

Miller, Michael L., and Cristian Vaccari. 2020. "Digital Threats to Democracy: Comparative Lessons and Possible Remedies." The International Journal of Press/Politics 25 (3): 333-56. https://journals.sagepub.com/doi/abs/10.1177/1940161220922323.

Molina, Maria D, and S Shyam Sundar. 2019. "Technological Affordances Can Promote Misinformation." In Journalism and Truth in an Age of Social Media, edited by James E. Katz and Kate K. Mays, 40-57. Oxford: Oxford University Press.

Newman, Nic, Richard Fletcher, Antonis Kalogeropoulos, and Rasmus Kleis Nielsen. 2019. “Reuters Institute Digital News Report 2019." Oxford, UK: Reuters Institute for the Study of Journalism. https://reutersinstitute.politics.ox.ac.uk/sites/default/files/201906/DNR_2019_FINAL_1.pdf.

Nyhan, Brendan, Ethan Porter, Jason Reifler, and Thomas J. Wood. 2019. "Taking Fact-Checks Literally But Not Seriously? The Effects of Journalistic Fact-Checking on Factual Beliefs and Candidate Favorability." Political Behavior 0 (0): 1-22. https://doi.org/10.1007/s11109-019-09528-x.

O’Neill, Deirdre, and Tony Harcup. 2019. "News Values and News Selection.” In The Handbook of Journalism Studies, edited by Karin Wahl-Jorgensen and Thomas Hanitzsch, 2nd ed., 213-28. New York: Routledge. https://doi.org/10.4324/9781315167497-14.

Orr, Caroline. 2019. “Twitter Bots Boosted the Trending \#TrudeauMustGo Hashtag.” National Observer, July 18, 2019. https://www.nationalobserver.com/2019/07/18/news/twitterbots-boosted-trending-trudeaumustgo-hashtag. 
Oved, Marco Chown. 2019. “Anatomy of a Manufactured Election Scandal.” The Star, October 9, 2019. https://www.thestar.com/politics/federal/2019/10/09/anatomy-of-amanufactured-election-scandal.html.

Paris, Britt, and Joan Donovan. 2019. "Deepfakes and Cheap Fakes.” New York: Data \& Society Research Institute. https://datasociety.net/output/deepfakes-and-cheap-fakes/.

Patterson, Thomas E. 2017. “Game versus Substance in Political News.” In The Oxford Handbook of Political Communication, edited by Kate Kenski and Kathleen Hall Jamieson, 377-90. Oxford University Press.

Phillips, Whitney. 2018. “The Oxygen of Amplification.” New York: Data \& Society Research Institute. https://datasociety.net/output/oxygen-of-amplification/.

Posetti, Julie. 2018. "News Industry Transformation: Digital Technology, Social Platforms and the Spread of Misinformation and Disinformation.” In Journalism, 'Fake News' \& Disinformation: Handbook for Journalism Education and Training, edited by Cherilyn Ireton and Julie Posetti, 55-69. France: UNESCO. https://en.unesco.org/sites/default/files/journalism_fake_news_disinformation_print_frien dly_0.pdf.

Public Policy Forum. 2017. "The Shattered Mirror: News, Democracy, and Trust in the Digital Age.” Ottawa, ON: Public Policy Forum. https://shatteredmirror.ca/wpcontent/uploads/theShatteredMirror.pdf.

Rocha, Roberto. 2018. "Data Sheds Light on How Russian Twitter Trolls Targeted Canadians." CBC News, August 3, 2018. https:/www.cbc.ca/news/canada/russian-twitter-trollscanada-targeted-1.4772397.

Rogers, Kaleigh, and Andrea Bellemare. 2019. "Misinformation Circulating Online Stokes Fears of Voter Fraud Ahead of Federal Election.” CBC News, August 30, 2019. https://www.cbc.ca/news/technology/voter-fraud-confusion-misinformation-1.5264689.

Rollwagen, Heather, Ivor Shapiro, Geneviève Bonin-Labelle, Lindsay Fitzgerald, and Lauriane Tremblay. 2019. "Just Who Do Canadian Journalists Think They Are? Political Role Conceptions in Global and Historical Perspective." Canadian Journal of Political 
Science/Revue Canadienne de Science Politique 52 (3): 461-77.

https://doi.org/10.1017/S0008423919000015.

RTDNA / Ipsos. 2019. "In Era of Fake News, Trust in Traditional News Sources Rebounding." Radio Television Digital News Association / Ipsos. http://www.rtdnacanada.com/in-eraof-fake-news-trust-in-traditional-news-sources-rebounding/.

Silverman, Craig, and Lawrence Alexander. 2016. "How Teens In The Balkans Are Duping Trump Supporters With Fake News.” BuzzFeed. November 3, 2016. https://www.buzzfeed.com/craigsilverman/how-macedonia-became-a-global-hub-for-protrump-misinfo.

Silverman, Craig, Alex Boutilier, Jane Lytvynenko, and Marco Chown Oved. 2019. "How A Canadian Yellow Vest Site Used Fake Accounts And Marketing Savvy To Monetize Outrage." BuzzFeed News, February 7, 2019. https://www.buzzfeed.com/craigsilverman/canada-yellow-vest-site-internet-marketer.

Silverman, Craig, Jane Lytvynenko, Alex Boutilier, and Marco Chown Oved. 2019. "Canada's New Partisan Media Is Poised To Ride a Facebook Wave To Election Day." BuzzFeed News, July 24, 2019. https://www.buzzfeednews.com/article/craigsilverman/canadapartisan-media-ontario-proud-north99.

Silverman, Craig, Jane Lytvynenko, and Marco Chown Oved. 2019. "The Buffalo Chronicle Ran Facebook Ads Promoting Dubious Trudeau Stories.” BuzzFeed News, October 29, 2019. https://www.buzzfeednews.com/article/craigsilverman/facebook-let-the-buffalochronicle-run-ads-for-trudeau.

Silverman, Craig, Lam Thuy Vo, and Jane Lytvynenko. 2018. "How Facebook Groups Are Being Exploited To Spread Misinformation, Plan Harassment, And Radicalize People.” BuzzFeed. March 19, 2018. https://www.buzzfeed.com/craigsilverman/how-facebookgroups-are-being-exploited-to-spread.

Strömbäck, Jesper, and Adam Shehata. 2010. "Media Malaise or a Virtuous Circle? Exploring the Causal Relationships between News Media Exposure, Political News Attention and Political Interest." European Journal of Political Research 49 (5): 575-97. https://doi.org/10.1111/j.1475-6765.2009.01913.x. 
Tandoc, Jr., Edson C., Joy Jenkins, and Stephanie Craft. 2019. "Fake News as a Critical Incident in Journalism." Journalism Practice 13 (6): 673-89. https://doi.org/10.1080/17512786.2018.1562958.

Tenove, Chris. 2020. "Protecting Democracy from Disinformation: Normative Threats and Policy Responses.” The International Journal of Press/Politics 25 (3): 517-37. https://doi.org/10.1177/1940161220918740.

Tenove, Chris, Jordan Buffie, Spencer McKay, David Moscrop, and Mark Warren. 2018. "Digital Threats to Democratic Elections: How Foreign Actors Use Digital Techniques to Undermine Democracy.” Working Paper Series. Vancouver: Centre for the Study of Democratic Institutions, University of British Columbia. https://democracy.arts.ubc.ca/2018/01/18/digital-threats/.

Tenove, Chris, and Heidi Tworek. 2019. "Online Disinformation and Harmful Speech: Dangers for Democratic Participation and Possible Policy Responses." Journal of Parliamentary and Political Law 13: 215-32.

Tolley, Erin. 2016. Framed: Media and the Coverage of Race in Canadian Politics. Vancouver, BC: UBC Press.

“Torstar Journalistic Standards Guide.” 2018. The Star. September 6, 2018. https://www.thestar.com/about/statementofprinciples.html.

U.S. Senate. 2019. "Report on Russian Active Measures Campaigns and Interference in the 2016 U.S. Election, Volume 2: Russia’s Use of Social Media with Additional Views." Washington, DC: United States Senate Select Committee on Intelligence. https://www.intelligence.senate.gov/sites/default/files/documents/Report_Volume2.pdf.

Vos, Tim P. 2019. “Journalists as Gatekeepers.” In The Handbook of Journalism Studies, 2nd ed. Taylor \& Francis. https://doi.org/10.4324/9781315167497-6.

Wardle, Claire. 2018. "5 Lessons for Reporting in an Age of Disinformation.” Medium (blog). December 28, 2018. https://medium.com/1st-draft/5-lessons-for-reporting-in-an-age-ofdisinformation-9d98f0441722.

Wardle, Claire, and Hossein Derakhshan. 2017. "Information Disorder: Toward an Interdisciplinary Framework for Research and Policy Making.” Report DGI(2017)09. 
Strasbourg: Council of Europe. https://firstdraftnews.com/wpcontent/uploads/2017/10/Information_Disorder_FirstDraft-CoE_2018.pdf?x56713.

Wood, Thomas, and Ethan Porter. 2019. “The Elusive Backfire Effect: Mass Attitudes' Steadfast Factual Adherence." Political Behavior 41 (1): 135-63. https://doi.org/10.1007/s11109018-9443-y.

Woolley, Samuel C., and Douglas Guilbeault. 2017. "Computational Propaganda in the United States of America: Manufacturing Consensus Online.” Working Paper 2017.5. Computational Propaganda Research Project, University of Oxford. http://comprop.oii.ox.ac.uk/wp-content/uploads/sites/89/2017/06/Comprop-USA.pdf.

Zelinsky, Nathaniel A. G. 2017. "Foreign Cyber Attacks and the American Press: Why the Media Must Stop Reprinting Hacked Material.” The Yale Law Journal 127 (October): 286-314. https://www.yalelawjournal.org/forum/foreign-cyber-attacks-and-the-americanpress. 